\title{
Antraknoza jagode (Colletotrichum spp.)
}

\section{Sažetak}

Antraknoza je jedna od najvažnijih bolesti kultivirane jagode (Fragaria $x$ ananassa Duch.) širom svijeta a uzrokuje je nekoliko gljiva iz roda Colletotrichum: Colletotrichum acutatum, C. gloeosporioides i C. fragariae. Vrste iz roda Colletotrichum inficiraju sve organe jagode uzrokujući trulež korijena i korjenova vrata, pojavu nepravilnih pjega na listovima, nekroze na peteljkama lista i stolonima te pojavu udubljenih gotovo crnih lezija na plodu jagode. U radu su ukratko opisani simptomi antraknoze, životni ciklus $i$ epidemiologija te mjere zaštite.

Ključne riječi: antraknoza, jagoda, Fragariaxananassa, Colletotrichum spp.

\section{Uvod}

Antraknozu jagode mogu uzrokovati sljedeće vrste iz roda Colletotrichum: Colletotrichum acutatum Simmonds (Glomerella acutata Guerber i J.C. Corell), C. fragariae Brooks (sin. C. theobromicola Delacr.), C. dematium (Pers. ex Fr.) Grove i C. gloeosporioides (Penz.) Penz i Sacc. (teleomorf G. cingulata) (Stone.) Spauld\& Schrenk) (Howard i sur., 1992; Mass, 1998; Ivanović i sur., 2007; Cvjetković, 2010).Vrste iz roda Colletotrichum važni su uzročnici bolest jagode širom svijeta. Poslije sive plijesni (Botrytis cinerea), smatraju se jednim od najvažnijih patogena jagode u svjetu (Smith, 2008). Vrsta C. fragariae, prvi puta je zabilježena na Floridi 1931. (Brooks, 1931 cit. Smith, 2008) kao uzročnik venuća sadnica. Vrsta C. fragariae uglavnom uzrokuje antraknozu korijenova vrata jagode uzgajane u vrućim vlažnim područjima jugoistočne Amerike. U Sjedinjenim Američkim Državama također uzrokuje značajne gubitke u proizvodnji sadnica jagode (Smith, 2008). Kasnih 1970-tih u Arkansasu i Sj. Carolini iz sadnica na kojima su se uočavali simptomi truleži korjenova vrata, izoliran je vrsta C. gloeosporioides. Vrsta C. gloeosporioides je geografski više raširena i ima veći broj domaćina u odnosu na vrstu $C$. fragariae. Vrsta $C$. gloeosporioides uglavnom uzrokuje lezije na peteljkama, stolonima i korijenovu vratu jagode, ali može uzrokovati i antraknozu plodova (Smith, 1998). Osim na jagodi C. gloeosporioides može uzrokovati bolesti na avokadu, bajamu, jabuci, trešnji, vinovoj lozi, breskvi, šljivi, agrumima (Cvjetković, 2010; Freeman i sur., 1998). Kao uzročnik truleži plodova jagode vrsta $C$. acutatum je prvi puta opisana u Queenslandu, u Australiji (Simmonds, 1965 cit. Smith, 2008). lako napada sve nadzemne organe jagode $C$. acutatum najčešće uzrokuje antraknoze ploda prije i nakon berbe (Berrie i Burgess, 2003; Howard i sur., 1992; Mass 1998). U zadnje vrijeme $C$. acutatum ima sve veći značaj i kao uzročnik pjegavosti lista, lezija na stolonima i peteljkama te truleži korijenova vrata i korijena jagode (Freeman i Katan, 1997). U svijetu se navode izuzetno velike štete na jagodama uzrokovane vrstom C. acutatum. Prema Mertely i Peres (2012) vrsta C. acutatum može uzrokovati gubitke u prinosu veće od $70 \%$, ukoliko su nasadi podignuti osjetljivim sortama jagode. Berrie i Burgess (2003) navode gotovo totalne gubitke na sortama jagode neutralnog dana uzrokovane vrstom C. acutatum na području Ujedinjenog Kraljevstva.

Mladen Zovko, dipl.ing.agr., prof. dr. sc. Ivan Ostojić, Sveučilište u Mostaru Agronomski i prehrambeno-tehnološki fakultet, Biskupa čule bb, 88000 Mostar, Bosna i Hercegovina

Prof.dr.sc. Tihomir Miličević, Sveučilište u Zagrebu Agronomski fakultet, Svetošimunska cesta 25, 10000 Zagreb, Hrvatska Autor za korespondenciju: mladen.zovko@aptf.sum.ba 
Freeman i Katan (1997) navode pojavu antraknoze jagode uzrokovane vrstom C. acutatum u epidemijskim razmjerima u Izraelu. Ivanović i sur. (2007) su u Srbiji zabilježili gubitke u prinosu preko $80 \%$ uzrokovane antraknozom ploda jagode, a slične gubitke navode i Denoyes i Baudry (1991) u Francuskoj na sortama jagode neutralnog dana. Prvi nalazi vrste C. acutatum na području Bosne i Hercegovine zabilježeni su na većem broju lokaliteta (Banja Luka, Gradiška, Laktaši), a postotak oboljelih biljaka kretao se od 5-20\% (Trkulja i sur., 2008). Osim na jagodi $C$. acutatum uzrokuje bolest na mnogim kultiviranim i korovskim biljnim vrstama, među kojima su posebnmo važne: jabuka, kruška, breskva, nektarina, kajsija, šljiva, višnja, kupina, borovnica, grožđe, kivi, paprika, rajčica, krastavac, tikvica, lubenica, soja, lucerna, Vicia spp., Anemone spp. (Smith i Black, 1990; Howard i sur., 1992; Trkulja i sur., 2008). Berrie i Burgess (2003) navode 35 korovskih vrsta na kojima je utvđena vrsta $C$. acutatum, međutim, na samo sedam korovskih vrsta bili su vidljivi simptomi bolesti, što pokazuje da vrsta $C$. acutatum može živjeti na biljkama i kao epifit i kao endofit, ne uzrokujući vidljive simptome (Leandro i sur., 2001). Tijekom povijesti smatralo se da je vrsta $C$. acutatum patogen koji uzrokuje trulež plodova, a vrste $C$. fragariae i C. gloeosporioides kao uzročnici lezija na peteljkama i stolonima te truleži korijenovog vrata, međutim, sve tri vrste mogu uzrokovati veoma slične simptome, i moguće ih je pronaći na istoj biljci u isto vrijeme (Howard i sur., 1992).

\section{Simptomibolesti}

Na temelju simptoma bolesti u polju teško je odrediti koja je od vrsta uzročnik antraknoze (Cvjetković, 2010). Prvi simptomi truleži korjenova vrata jagode uzrokovane vrstama C. fragariae ili $C$. gloeosporioides, manifestiraju se u vidu venuća najmlađih listova tijekom najtoplijeg dijela dana. Mladi listovi mogu se u večernjim satima oporaviti, povratiti turgor, međutim većinom venu i odumiru u narednih nekoliko dana. Ubrzo nakon što biljka uvene, unutar tkiva korijenova vrata pojavljuje se crvenkasto smeđa boja centralnog cilindra. Nekoliko dana kasnije tkivo vrata korijena mijenja boju u tamno smeđu i tada je vrlo teško izolirati uzročnika bolesti (Smith, 1998). Korijenje i stoloni mogu se zaraziti samo kroz oštećena mjesta što se često događa za vrijeme vađenja sadnica, prilikom njihove manipulacije i transporta (Cvjetković, 2010). Zaražene biljke obično nakon sadnje zaostaju u rastu ostaju kržljave, ali rijetko ugibaju (Freeman i Katan, 1997; Smith, 1998). Sve tri vrste Colletotrichum spp. mogu uzrokovati pojavu tamno smeđih do crnih vodenastih lezija na peteljkama i stolonima, lezije su jasno odvojene od zdravog tkiva. Simptomi koji nastaju na peteljkama i stolonima u suhim i hladnim područjima uzgoja jagode često prođu nezamijećeni (Curry i sur., 2002). Ukoliko lezija prstenasto zahvati peteljku lista ili stolona, dolazi do prekida u snabdijevanju listova i stolona vodom i hranjivima te se oni suše. Često na samim lisnim peteljkama dolazi do obilne sporulacije, što doprinosi brzom širenju patogena u nasadu (Trkulja i sur., 2008). Sve tri vrste mogu uzrokovati pojavu pjega na listu jagode (Howard i sur., 1992; Smith, 1998). Pjege uzrokovane vrstama $C$. fragariae i $C$. gloeosporioides obično su sive ili crne boje, promjera 1-3 mm. Pjege su prisutne po cijeloj površini lica lista i obično ne nekrotiziraju. Vrsta $C$. acutatum uzrokuje pojavu nepravilnih pjega, čiji simptomi počinju u vidu nekrotičnih crnih lezija na vrhu plojke lista. lako se ponekad pjege na listu jave u većoj brojnost, rijetko uzrokuju sušenje lista (Ivanović i Ivanović, 2005). Vrsta C. acutatum može sporulirati na listovima jagode bez vidljivih simptoma (Leandro i sur., 2001), što objašnjava iznenadnu pojavu simptoma na plodovima bez prisutnosti simptoma na drugim dijelovima biljke. Sve tri vrste Colletotrichum spp. uzrokuju palež cvijeta i trulež plodova (Smith, 1998). Otvoreni cvjetovi puno su osjetljiviji u odnosu na zatvorene cvjetne pupove (Smith, 2008). Zaraženi cvjetni pupovi se suše i poprimaju svijetlo smeđu boju i izvor su inokuluma za kasniju zarazu plodova (Ivić, 2015). Početni simptomi na plodovima jagode javljaju se u vidu malih svijetlih kružnih, u početku vodenastih, blago uleglih pjega (Berrie i Burgess, 2003; Ivano- 
vić i sur., 2007; Trkulja i sur., 2008). Inficirani zeleni plodovi obično ne sazrijevaju, nego mijenjaju boju u smeđu, suše se i mumificiraju (Smith, 2008). Antraknoza je ipak najčešća na plodovima koji se približavaju zrelosti ili su zreli za berbu (Ivić, 2015). U optimalnim uvjetima temperature i vlažnosti, patogen se brzo razvija, pa za tri do četiri dana nastaju tamne, ovalne, udubljene lezije promjera 1-2 cm, često prekrivene kapljicama ružičaste boje (Slika 1). Ružičaste kapljice predstavljaju nakupine spora gljive, koje se u obilju stvaraju u acervulima razvijenih u lezijama (Ivić, 2015). Ovisno od koncentracije inokuluma, kao i vremenskih uvjeta, na plodu se može razviti jedna ili više pjega, koje se međusobno spajaju te ubrzo cijeli plod biva zahvaćen (Trkulja i sur., 2008). Latentni period od vremena infekcije ploda do pojave prvih simptoma prosječno traje 2 do 3 dana pri temperaturi od $25^{\circ} \mathrm{C}$, dok pri temperaturi od $5^{\circ} \mathrm{C}$ latentni period traje 6 do 17 dana (King i sur., 1997). Ponekad se na plodovima ne primjećuju pjege u vrijeme berbe, ali dok stignu na tržište mnogi plodovi ispoljavaju simptome antraknoze (Ivanović i sur., 2007). Pri toplom i vlažnom vremenu na površini unutar pjega parazit sporuliše, stvarajući micelijsku prevlaku s obiljem konidija ružičaste, bijele ili narandžaste boje. Na kraju patogen zahvati cijeli plod, uzrokujući njegovo sušenje i mumificiranje (Trkulja i sur., 2008; 2015).

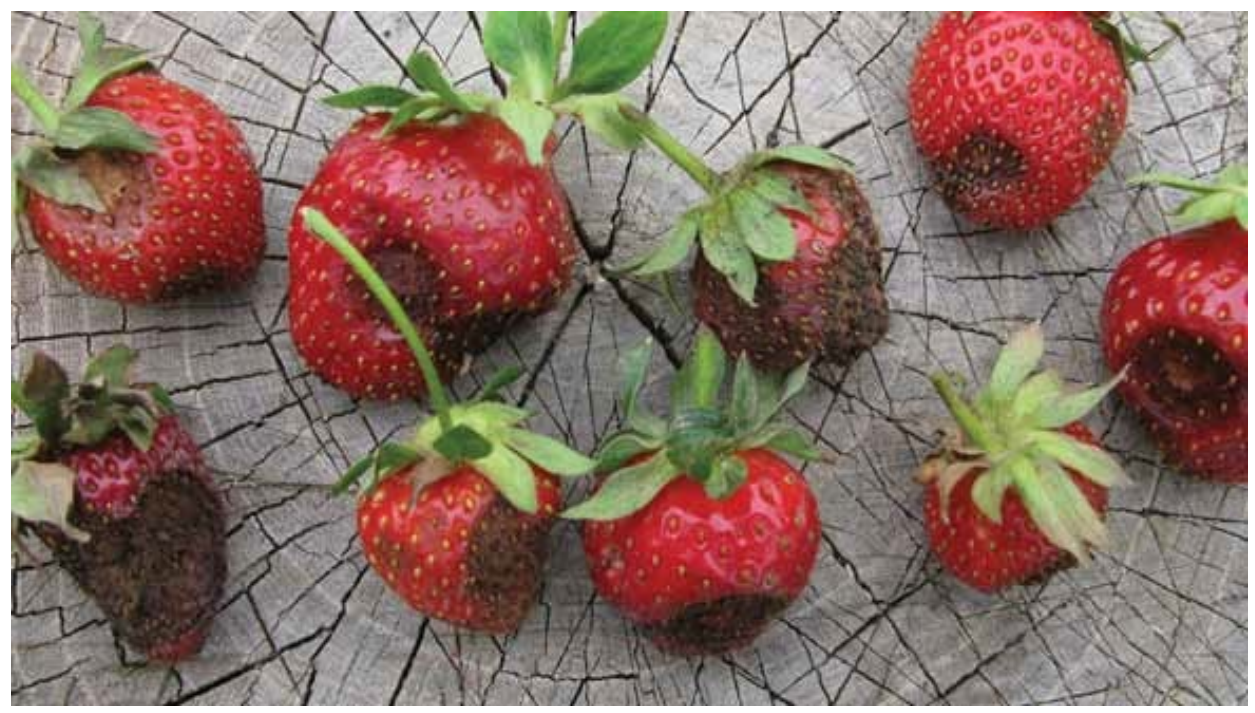

Slika 1. Simptomi antraknoze na plodovima jagode (foto: Zovko, M.)

Figure 1. Strawberry fruits with symptoms of anthracnose (photo: Zovko, M.)

\section{Parazit}

Izolati $C$. fragariae u kulturi stvaraju bež do maslinasto zelene i tamno sive kolonije. Konidije su cilindrične, jedan kraj je oštro sužen, drugi zaobljen (Smith i Black, 1990), veličine 14-21 x 3,9-6,3 $\mu \mathrm{m}$ (Mass, 1998). Savršeni stadij nije poznat. Izolati vrste $C$. gloeosporioides na hranjivoj podlozi stvaraju svijetlosive do tamnosive kolonije. Konidije su veličine 9-24 x 3-6 $\mu \mathrm{m}$, zaobljene na oba kraja. Savršeni stadij Glomerella cingulata. Izolati $C$. fragariae i $C$. gloeosporioides imaju crne sete, vidljive ručnim povećalom, u acervulima u kulturi, kao i u lezijama na peteljkama, stolonima i plodovima (Smith i Black, 1990). Na hranjivoj podlozi izolati $C$. acutatum obrazuju bujnu miceliju obično bijele, svijetlo-sive, svijetlo-roze pa do vinsko-ružičaste boje, bez seta. Konidije $C$. acutatum su jednostanične, glatke, hijaline, elipsoidne, zaoštrene na oba kraja (fusiformne) dimenzija 13,3-(15,4)-17,4 x 3,7-(4,0)-4,4 $\mu$ m (Trkulja i sur., 2008). Konidije prilikom 
klijanja direktno na konidiji ili na kraćoj ili dužoj inicijalnoj hifi stvaraju apresorije. Apresoriji su svijetlo do tamno smeđe boje, veličine 6,5-11 x 4,5-7,5 $\mu \mathrm{m}$ (Gunell i Gubler, 1992). Najčešće na jednoj konidiji nastaje jedna, a rjeđe dvije do tri apresorije (Smith i Black, 1990; Howard i sur., 1992; Trkulja i sur., 2008). Tijekom proučavanja morfoloških karakteristika izolata vrste $C$. acutatum Trkulja i sur. (2008) navode da nisu utvrdili prisutnost/formiranje peritecija ni u kulturi niti na umjetno inokuliranim plodovima, kao ni na lisnim peteljkama. lako je poznat njihov spolni stadij (peritecij s askosporama, rod Glomerella) i može se naći u prirodi, smatra se da taj stadij nema ulogu u epidemiologiji na jagodama (Ivić, 2015).

\section{Životni cikus i epidemiologija}

Fitopatogena gljiva $C$. acutatum se od jedne do druge vegetacije održava na inficiranim biljkama jagode, zaraženim biljnim ostatcima, kontaminiranom zemljištu ili korovskim vrstama u i oko nasada jagode (Eastburn i Gubler, 1990; Howard i sur., 1992), dok se na veće udaljenosti prenosi zaraženim sadnicama (Berrie i Burgess, 2003). Gljive iz roda Colletotrichum ne stvaraju trajne strukture koje bi im mogle omogućiti dugotrajno prezimljenje, održavanje i nagomilavanje u tlu (Ivić, 2015). Eastburn i Gubler (1990) navode da vrsta C. acutatum može preživjeti u tlu na zaraženom biljnom tkivu i do 9 mjeseci. U ekološkim uvjetima Skandinavije vrsta $C$. acutatum može u tlu ili na površini tla u biljnim ostatcima preživjeti gotovo 3 godine (Parikka i sur., 2016). Prema Eastburn i Gubler (1992) temperatura i vlažnost igraju važnu ulogu u preživljavanju vrste $C$. acutatum. Visoke temperature i prevelika vlažnost uzrokuju brzo propadanje gljive, za razliku od niskih temperatura tijekom zime koje pogoduju prezimljavanju, budući da je u takvim uvjetima smanjena aktivnost kompeticijskih mikroorganizama. Ljilja i sur. (2006) navode da su uspjeli umjetno inokulirati mlade biljke jagoda vrstom $C$. acutatum izoliranom iz inficiranih biljnih ostataka koji su u polju bili dvije godine, što ukazuje da vrsta $C$. acutatum može preživjeti visoke ljetne temperature, kao i visoku vlažnost tla. Vrsta $C$. acutatum može prezimjeti i na kultiviranim vrstama poput paprike, patlidžana, rajčice, graha te brojnim korovskim biljnim vrstama, bez da na njima uzrokuje pojavu simptoma bolesti te alternativni domaćini mogu biti izvor inokuluma između dvije uzgajivačke sezone (Freeman i sur., 2001; Freeman, 2008;). Izvor zaraze mogu biti i lezije na peteljkama, kao i konidije koje nastaju na odumrlim listovima jagode (MacKenzie i Peres, 2012). U polju se gljiva najčešće širi konidijama, koje kapi kiše raznose po nasadu (Madden i sur., 1993; Mertely i Peres, 2012). Spore lete na kratke udaljenosti, nisu aerodinamične i vjetar ih gotovo ne raznosi (Ivić, 2015). Spore mogu prenositi i sami berači jagode na rukama i odjeći. Norman i Strandberg (1997) navode da konidije na odjeći berača mogu zadržati vitalnost i do pet tjedana. Udaljenost širenja konidija kišnim kapima kao i pojava bolesti je u korelaciji sa intenzitetom i trajanjem kišenja (Madden i sur., 1996). Na pojavu i intenzitet bolesti veliki utjecaj imaju vremenski uvjeti, a najveće štete gljiva pričinjava u toplim i vlažnim područjima (Peres i sur., 2005). Wilson i sur. (1990) navode da su optimalne temperature za infekciju ploda jagode između 25 i $30^{\circ} \mathrm{C}$ uz 13 sati vlaženja. Osim dužine perioda vlaženja na pojavu i intenzitet bolesti znatno utječe i koncentracija inokuluma patogena (Forcelini, 2017). Pri toplom i vlažnom vremenu patogen stvara obilje konidija, koje kišne kapi raznose na plodove i druge organe. Konidije klijaju u vidu micelije koja se završava aprsorijima, hife probijaju kutikulu i rastu u epidermalnim i subepidermalnim stanicama. Za uspješno klijanje konidija pri temperaturi od 21 do $33^{\circ} \mathrm{C}$ neophodno je minimalno 4 sata vlaženja (Leandro i sur., 2003). 


\section{Mjere zaštite}

Kontrola antraknoze jagode zahtijeva integralni pristup u kojemu agrotehničke mjere imaju veliku važnost kao i primjena fungicida. Najvažnija mjera kontrole bolesti je sadnja nazaraženog sadnog materijala, i to sorti koje su otpornije prema bolesti (Ivanović i Ivanović, 2005; Trkulja i sur., 2015). Otporne sorte jagode mogle bi biti najučinkovitiji i ekonomski najisplativiji način zaštite od antraknoze, no veći broj danas raširenih i tržišno prihvaćenih sorti osjetljiv je na antraknozu (Berrie i Burgess, 2003; Ivić, 2015). Kao vrlo osjetljive pokazali su se sorte 'Marmolada' i 'Elsanta', a osjetljivima se smatraju 'Miss', 'Raurica', 'Miranda', 'Alba' i 'Madeleine'. Slabije osjetljive sorte na antraknozu su 'Queen Elisa', 'Irma', 'Roxana', 'Idea' i 'Patty' (Ivić, 2015). Trkulja i sur. (2008) navode sorte 'Selena' i Honeoye' kao osjetljive na antraknozu uzrokovanu vrstom C. acutatum. Latinović i sur. (2012) navode značajne štete na sorti 'Clery' uzrokovane vrstom $C$. acutatum. Prema Ivanović i sur. (2007) sorta 'Marmolada' je vrlo osjetljiva na antraknozu, budući da je zaraza plodova na ovoj sorti pojedinih godina u Srbiji bila preko 80\%. Forcelini (2017) navodi sorte 'Treasure' i 'Camarosa' kao vrlo osjetljive na antraknozu. Testiranjem 13 različitih sorti jagode na osjetljivost prema antraknozi, Seijo i sur. (2008) kao rezistentne sorte navode: 'Florida Radiance', 'Florida Elyana' i 'Sweet Charlie', a kao vrlo osjetljive sorte navode 'Treasure', 'Camarosa' i 'Albion'. MacKenzie i Peres (2012) također navode sortu 'Camarosa' kao osjetljivu na antraknozu, a postotak zaraženih plodova ovisno o godini može biti od 8,3 do 58,4\%. Međutim, čak i umjereno otporne sorte jagode su u opasnosti od zaraze ukoliko se uzgajaju u blizini većih nasada podignutih sa osjetljivim sortama (Forcelini, 2017).

Važna mjera kontrole antraknoze jagode je plodosmjena u trajanju od 1 do 3 godine te suzbijanje korova u i oko nasada, posebno bijele djeteline (Trifolium repens L.) (Parikka i sur., 2016). Jagodu treba uzgajati u plodoredu sa kulturama koje nisu domaćini Colletotrichum spp. te na taj način smanjiti sadržaj inokuluma patogena (Trkulja i sur., 2015). Kako bi se smanjila mogućnost širenja konidija vodom, u područjima u kojima postoji potreba za navodnjavanjem, navodnjavanje treba provoditi sustavom natapanja kap po kap (Freeman, 2008). Odstranjivanje mumificiranih plodova, listova sa simptomima bolesti i zaraženih biljnih ostataka iz nasada, kao i druge mjere higijene svakako su korisne jer doprinose smanjenju infektivnog inokuluma patogena (Smith, 2008; Trkulja i sur., 2008). Pojava antraknoze ploda veća je u nasadima pokrivenim plastičnim malč folijama u odnosu na parcele prekrivene slamom ili nasade podignute na golom tlu (Madden i sur., 1993). Uzgojem jagode u zaštićenim prostorima onemogućeno je prenošenje konidija kišom te se izbjegava pojava antraknoze i smanjuje rizik od pojave sive plijesni, ali se $u$ isto vrijeme povećava rizik od pojave pepelnice (Berrie i Burgess, 2003). Antraknozu je moguće suzbijati tretiranjem fungicidima od pojave cvjetnih pupova pa tijekom berbe (Mass, 1998). Za efikasno suzbijanje antraknoze jagode od iznimne je važnosti pravovremena primjena fungicida (Forcelini, 2017). Na Floridi se za preventivno suzbijanje antraknoze uzrokovane vrstom C. acutatum koriste pripravci na osnovi kaptana (Mertely i Peres, 2012). Jednom kada se uoče simptomi bolesti u polju preporučuje se primjena pripravaka na osnovi azoksistrobina i piraklostrobina u kombinaciji sa nekim kontaktnim pripravkom (Daugovish i sur., 2009). Ukoliko se uzgajaju visoko osjetljive sorte jagode, pripravke na osnovi azoksistrobina i piraklostrobina potrebno je primijeniti u punoj cvatnji (Forcelini, 2017). Učinkovitim na antraknozu pokazali su se pripravci na osnovi aktivnih tvari boskalid + piraklostrobin i fludioksonil + ciprodinil koji se koriste za suzbijanje sive plijesni jagode (Ivić, 2015). U područjima gdje se antraknoza javlja, zaštitu plodova potrebno je kombinirati sa zaštitom od sive plijesni. Prema Smith (1998) brojni izolati patogena su rezistentni prema benomilu, a u novije vrijeme utvrđena je rezistentnost vrste $C$. acutatum na Qol kemijsku skupinu fungicida (Forcelini i Peres, 2018). Herbicidi poput parakvata i glifosata potiču sporulaciju vrste C. acutatum (Cerkauskas, 1988). 


\section{Literatura}

Berrie, M.A., Burgess, M.C. (2003) A review of research on epidemiology and control of blackspot of strawberry (Colletotrichum acutatum) with special reference to weeds as alternative hosts. Integrated Plant Protection in Orchards - Soft Fruits IOBC/wprs Bull. Vol. 26(2) pp. 163-168.

Brooks, A.N. (1931) Anthracnose of strawberry caused by Colletotrichum fragariae, n. sp. Phytopathology 21:739744.

Cerkauskas, R.F. (1988) Latent colonisation by Colletotrichum spp: Epidemiological considerations and implications for mycoherbicides. Canadian Journal of Plant Pathology 10: 297-310.

Curry, K.J., Abril, M., Avant, J.B., Smith, B.J. (2002) Strawberry anthracnose: Histopathology of Colletotrichum acutatum i C. fragariae. Phytopathology 92: 1055-1063.

Cvjetković, B. (2010) Mikoze i pseudomikoze voćaka i vinove loze. Zrinski d.d., Čakovec.

Daugovish, O., Su, H., Gubler, W.D. (2009) Preplant fungicide dips of strawberry transplants to control anthracnose caused by Colletotrichum acutatum in California. Hort Technology 19: 317-323.

Denoyes, B., Baudry, A. (1991) Characterization of species of Colletotrichum isolated from strawberry in France: taxonomy and pathogenicity. Strawberry Diseases and Breeding for Varietal Resistance. International Workshop, Bordeaux, abstract.

Eastburn, D.M., Gubler, W.D. (1990) Strawberry anthracnose: Detection and Survival of Colletotrichum acutatum in Soil. Plant Diseases 74: 161-163.

Forcelini, B.B. (2017) Effect of inoculum concentration and interrupted wetness duration on the development of anthracnose fruit rot of strawberry. Plant Disease, Vol. 101, No. 2 p. 372-377.

Forcelini, B.B., Peres, A.N. (2018). Widespread Resistance to Qol Fungicides of Colletotrichum acutatum from Strawberry Nurseries and Production Fields. Plant Health Progress, Vol. 19, No. 4, p. 338-341.

Freeman, S. (2008) Management, survival strategies and host range of Colletotrichum acutatum on strawberry. HortScience 43: 66-68.

Freeman, S., Horowitz, S., Sharon, A. (2001) Pathogenic and nonpathogenic lifestyles in Colletotrichum acutatum from strawberry and other plants. Phytopathology 91:986-992.

Freeman, S., Katan, T. (1997) Identification of Colletotrichum species responsible for anthracnose and root necrosis of strawberry in Israel. Phytopathology 87:516-521.

Freeman, S., Katan, T., Shabi, E. (1998) Characterizationof Colletotrichum species responsiblefor anthracnose diseases of various fruits. Plant Disease. 82:596-605.

Gunnell, P.S., Gubler, W.D. (1992). Taxsonomy and morphology of Colletotrichum species pathogenic to strawberry. Mycologia 84, 157-165.

Howard, C., Mass, J.L., Chandler, C.K., Albregts, E.E. (1992) Anthracnose of strawberry caused by the Colletotrichum complex in Florida. Plant Dis. 76:976-981.

Ivanović, M., Ivanović, D. (2005) Bolesti voćaka i vinove loze i njihovo suzbijanje. Grafiprof, Beograd. 498.

Ivanović, S.M., Duduk, B.B., Ivanović, M.M., Ivanović, S.M. (2007) Nova bolest jagode u Srbiji. Biljni lekar, 5; 491-

Ivić, D. (2015) Antraknoza jagode (Colletotrichum spp.). Glasilo biljne zaštite, Vol. 15 (5): 354-359.

King, W.T., Maddeen, L.V, Ellis, M.A., Wilson, L.L. (1997) Effects of temperature on sporulation and latent period of Colletotrichum spp. infecting strawberry fruit. Plant Dis. 81:77-84.

Latinovic, J., Latinovic, N., Tiodorovic, J., Odalovic, A. (2012) First report of anthracnose fruit rot of strawberry caused by Colletotrichum acutatum in Montenegro. Plant Disease Volume 96, Number 7, Page 1066.

Leandro, L.F.S., Gleason, M.L., Nutter, F.W., Jr., Wegulo, S.N., Doxon, P.M. (2001) Germination and Sporulation of Colletotrichum acutatum on Symptomless Strawberry Leaves. Phytopathology 91: 659-664.

Leandro, L.F.S., Gleason, M.L., Nutter, F.W., Jr., Wegulo, S.N., Doxon, P.M. (2003) Influence of temperature and wetness duration on conidia and appressoria of Colletotrichum acutatum on symptomless strawberry leaves. Phytopathology 93: 513-520.

Lilja, A., Parikka, P., Pääskynkivi, E., Hantula, J., Vainio, E., Vartiamäki, H., Lemmetty, A. Vestberg, M. (2006)

Phytophthora cactorum and Colletotrichum acutatum: survival and detection. - Agriculturae conspectus scientificus 71 (4): 121-128.

Maas, J.L. (1998) Compendium of strawberry diseases. Saint Paul: American Phytopathological Society Press. MacKenzie, J.S., Peres, N.A. (2012) Use of leaf wetness and temperature to time fungicide applications to control anthracnose fruit rot of strawberry in Floridi. Plant Dis. 96:522-528.

Madden, L.V., Yang, X., Wilson, L.L. (1996) Effects of rain intensity on splash dispersal of Colletotrichum acutatum. Phytopathology 86:864-874.

Madden, L.V., Wilson, L.L., Ellis, M.A. (1993) Field spread of anthracnose fruit rot of strawberry in relation to ground cover and ambient weather conditions. Plant Dis. 77:861-866.

Mertely, J.C., Peres, N.A. (2012) Anthracnose Fruit Rot of Strawberry. Publ. No. PP-207. University of Florida, IFAS, EDIS, Gainesville.

Norman, D. J., Strandberg, O. J. (1997) Survival of Colletotrichum acutatum in soil and plant debris of leatherleaf fern. Plant Dis. 81:1177-1180.

Parikka, P., Lemmetty, A., Sundelin, T., Strømeng, G.M., Stensvand, A. (2016) Survival of Colletotrichum acutatum in plant residue. Acta Hortic. 1117, 177-180. 784-796.

Seijo T.E., Chandler, C.K., Mertely, J.C., Moyer, C., Peres, N.A. (2008). Resistance of strawberry cultivars and advanced selections to anthracnose and Botrytis fruit rots. Proceedings of the Florida State Horticultural Society 121, 246-8. 
Simmonds, J. H. (1965) A study of the species of Colletotrichum causing ripe fruit rots in Queensland. Queensland J.Agr. Anim. Sci. 22:437-459.

Smith, B.J. (1998) Anthracnose fruit rots (black spot). In "Compendium of Strawberry Diseases" (Ed. J. L. Mass), pp. 31-33. APS Press, St. Paul, Minesota, USA.

Smith, B.J. (2008) Epidemiology and Pathology of Strawberry Anthracnose: A North American Perspective. HortScience. Vol 43(1) 69-73.

Smith, B.J., Black, L.L. (1990) Morphological, cultural and pathogenic variation among Colletotrichum species isolated from strawberry. Plant Dis. 74: 69-76.

Trkulja, V., Stojčić, J., Ćurković, B. (2008) Etiološko proučavanje pojave antraknoze jagode u sjeverozapadnom dijelu Bosne i Hercegovine. Glasnik zaštite bilja 5: 75-89, Zagreb.

Trkulja, V., Mitrić, S., Čivić, H., Karić, N., Ostojić, I., Mićić, N., Đurić, G., Cvetković, M., Pašalić, B., Radović, R., Jusović, H. (2015) Integralna proizvodnja jagodastog voća. Grafičar promet d.o.o., Sarajevo.

Wilson, L.L., Madden, L.V., Ellis, M.A. (1990) Influence of temperature and wetness duration on infection of immature and mature strawberry fruit by Colletotrichum acutatum. Phytopathology 80.111-116.

Prispjelo/Received: 12.1.2020.

Prihvaćeno/Accepted: 20.4.2020.

\section{Anthracnose of strawberry (Colletotrichum spp.)}

\section{Abstract}

Strawberry anthracnose is one of the most important diseases of strawberry (Fragaria $x$ ananassa Duch.) which caused by several species of fungi in the genus Colletotrichum: Colletotrichum acutatum, C. gloeosporioides and C. fragariae. Colletotrichum species infect all plant parts causing serious crown rot, irregular leaf spots, necrotic lesions on the petioles and stolons, as well as black spot on the fruits. Life cycle and epidemiology, disease symptoms and control measures are briefly described in the article.

Keywords: anthracnose, strawberry, Fragariaxananassa, Colletotrichum spp.



